\title{
Computer Control Of A PWM Induction Machine Drive System
}

\author{
Salah Ghazy Ramadan \\ BHIT - Benha Higher Institute of Technology \\ Benha - Egypt
}

\begin{abstract}
The aim of this paper is to study and realize a universal control scheme for a pulse width modulated drive system using the capability of digital computation in real time. Two microprocessor-systems and additional digital and analog circuits are implemented in order to fulfill that control scheme. The system speed would be dynamically changed for a wide range, starting from stand still up to twice the nominal speed in the field weakening range. Also at the same time, the maximum source voltages and currents are fully used. The implementation of the circuit to produce the firing pattern for the pulse width modulated inverter depends on voltage signals corresponding to the phase voltage instead of phase currents in order to eliminate the torque and field errors which will occur at high frequencies due to the inequality of the sinusoidal desired and actual currents.

The control system is tested using a $2.5 \mathrm{KW}$ squirrel cage motor and the obtained results prove that the system is stable and suitable to be implemented in industrial applications.
\end{abstract}




\section{List of Symbols}

\section{Signals}

i

I

$\mathrm{v}$

e

$\omega$

$\omega_{\text {mech }} ; \omega_{\mathrm{m}}$

$\Psi$

$\mathrm{T}_{\mathrm{e}} ; \mathrm{T}_{1}$
Current; Current component; Current vector

Current in vector diagram; effective value

Voltage

Induced voltage

Rotating frequency

\section{Machine Parameters}
$\mathrm{R}$
Resistance
L; M Inductance; Mutual inductance
J Inertia
$\sigma \quad$ - Total leakage factor
$\mathrm{K}_{11} \quad$ Factor of the inductance inverse matrix
$\mathrm{p} \quad$ Number of pole pairs
$\mathrm{T}_{\mathrm{O}} \quad$ Calculated short-circuit time constant on stator side

\section{Other Notations}

T Time constant; switching time

G Transfer function

$\mathrm{K}_{\mathrm{p}} \quad$ Proportional amplification factor of a controller

$\mathrm{K}_{\mathrm{I}} \quad$ Integration factor of a controller

$\Delta \quad$ Relative error

WMC; NC Speed controller

IC Current controller

VVC Voltage to voltage converter

CVC Current to voltage converter

PWI Pulse-width-inverter

FC Field calculating circuit

GC Transformation angle calculating circuit

CRT counter

AC Analog calculation circuit

DAC Digital to analog converter

\section{Indices}
S
Stator values
$\mathrm{r} \quad$ Rotor values
$\mathrm{a} ; \mathrm{b} ; \mathrm{c} \quad$ Values of the three-phase stator-fixed coordinates
$\alpha ; \beta \quad$ Values of the two orthogonal stator-fixed coordinates
$\mathrm{x} ; \mathrm{y} \quad$ Values of the rotating frame
d Desired values
a Actual values
m Mechanical Values
t Total value
the rarely used notations are clarified where used., 


\section{Introduction}

Since long time, the squirrel cage induction machine is used as a drive motor due to its simplified and robust construction. Today, drive systems of wide variable speed ranges are constructed by linking that type of induction machines with the modern semi-conductor elements. According to the control scheme and the used power electronics circuits the characteristics of the machine becomes, day after day, as of dc motors. Many types of power circuits are designed to fulfill such characteristics. One of them is the pulse width modulated drive system which will be studied in this work.

The general construction of a PWM drive system consists as shown in Fig. 1 of a dc voltage source, a pulse width modulated inverter (PWI), and a squirrel cage asynchronous machine (ASM). The voltage source may be a battery bank or a dc-converter followed by a suitable filter. According to the power of the machine, the inverter may be a transistorized or a thyristorized inverter. The implemented system consists of a three-phase dual-converter coupled with a three-phase transistorized inverter through an $\mathrm{L} / \mathrm{C}$ filter.

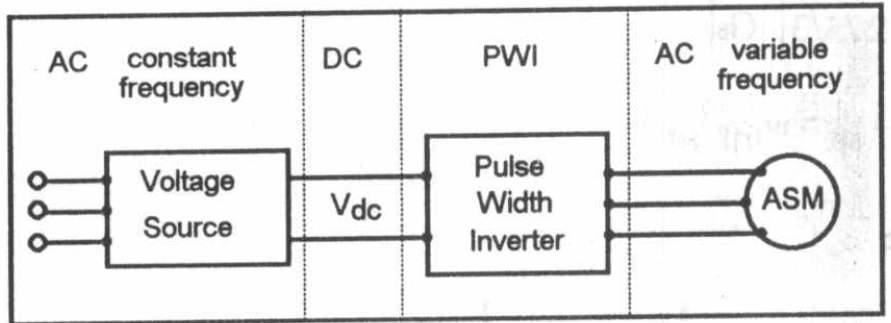

Fig.1 A PWM Drive System

\section{Machine Modeling}

Generally, the design of any control scheme depends on the characteristic of the different elements of the drive system. The main part of the system is the induction machine and therefore a suitable mathematical model for it will be obtained. Thereafter the control strategy and its implementation by a micro-computing system is performed.

The mathematical model of the ASM in the two orthogonal axis theorem has been studied in many works before as in $/ 1,2 /$ by using the following assumptions.

1. The iron losses and the magnetic saturation are neglected.

2. All parameters as resistors and inductors are constants.

3. The air-gap flux is sinusoidal.

4. The zero conductor is not connected.

By micro-computing system control, as by the performed system, the non-linearity of the machine is taken into consideration and hence, the first two assumptions are overcome. Here, for the implemented control scheme, the stator current $i_{\mathrm{S}}$ and the rotor flux $\psi_{\mathrm{r}}$ are chosen as state variables and hence the state-equations of the machine system are created after transforming the rotor flux $\psi_{\mathrm{r}}$ into the following form; 
$\psi=\frac{\mathbf{M}}{\mathbf{L}_{\mathbf{r}}} \cdot \psi_{\mathbf{r}}$

Referring to the ASM model shown in Fig.2 and inserting Eq. 1 into the analysis in /1 and 2/, the system equations of the ASM in normalized form can be rewritten in the stator fixed ( $\alpha$ $\beta$ ) coordinates as;

$\left|\begin{array}{c}\overline{\mathrm{i}}_{s \alpha} \\ \overline{\mathrm{i}}_{\mathrm{s} \beta} \\ \bar{\psi}_{\mathrm{tr} \alpha} \\ \overline{\bar{\psi}}_{\mathrm{tr} \beta}\end{array}\right|=\left|\begin{array}{cccc}-1 / \mathrm{T}_{0} & 0 & \mathrm{~K}_{11} / \mathrm{T}_{\mathrm{r}} & \mathrm{K}_{11} \omega_{\mathrm{m}} \\ 0 & -1 / \mathrm{T}_{\mathrm{o}} & -\mathrm{K}_{11} \omega_{\mathrm{m}} & \mathrm{K}_{11} / \mathrm{T}_{\mathrm{r}} \\ \mathrm{R}_{\mathrm{tr}} & 0 & -1 / \mathrm{T}_{\mathrm{r}} & -\omega_{\mathrm{m}} \\ 0 & \mathrm{R}_{\mathrm{tr}} & \omega_{\mathrm{m}} & 1 / \mathrm{T}_{\mathrm{r}}\end{array}\right| \cdot\left|\begin{array}{c}\mathrm{i}_{s \alpha} \\ \mathrm{i}_{s \beta} \\ \psi_{t r \alpha} \\ \psi_{\mathrm{tr} \beta}\end{array}\right|+\mathrm{K}_{111}\left|\begin{array}{c}\mathrm{v}_{\mathrm{s} \alpha} \\ \mathrm{v}_{\mathrm{s} \beta} \\ 0 \\ 0\end{array}\right|$

The three-phase (a-b-c) system has been transformed into the $(\alpha-\beta)$ by the formula;

$\left|\begin{array}{c}\mathrm{G}_{\alpha} \\ \mathrm{G}_{\beta}\end{array}\right|=\left|\begin{array}{cc}1 & 0 \\ 1 / \sqrt{3} & 2 / \sqrt{3}\end{array}\right| \cdot\left|\begin{array}{c}\mathrm{G}_{\mathrm{a}} \\ \mathrm{G}_{\mathrm{b}}\end{array}\right|$

$\mathrm{T}_{\mathrm{e}}=\mathrm{p} \cdot\left[\psi_{\operatorname{tr} \alpha} \cdot \mathrm{i}_{\mathrm{s} \beta}-\psi_{\operatorname{tr} \beta} \cdot \mathrm{i}_{\mathrm{s} \alpha}\right]$

$\mathrm{J} \cdot \bar{\omega}_{\text {mech }}=\mathrm{T}_{\mathrm{e}}-\mathrm{T}_{\mathrm{L}}$

where $\quad \mathbf{K}_{11}=\frac{\mathbf{L}_{\mathbf{r}}}{\mathbf{L}_{\mathbf{s}} \cdot \mathbf{L}_{\mathbf{r}}-\mathbf{M}^{2}}=\frac{1}{\sigma \mathbf{L}_{\mathbf{s}}}$

$\mathrm{R}_{\mathrm{tr}}=\left[\mathrm{M} / \mathrm{L}_{\mathrm{r}}\right]^{2} \cdot \mathrm{R}_{\mathrm{r}}$

$1 / \mathrm{T}_{\mathrm{o}}=\mathrm{K}_{11} \cdot\left(\mathrm{R}_{\mathrm{S}}+\mathrm{R}_{\mathrm{tr}}\right)$

$\mathrm{T}_{\mathrm{r}}=\mathrm{L}_{\mathrm{r}} / \mathrm{R}_{\mathrm{r}}$

$\omega_{\mathrm{m}}=\mathrm{p} . \omega_{\mathrm{mech}}$

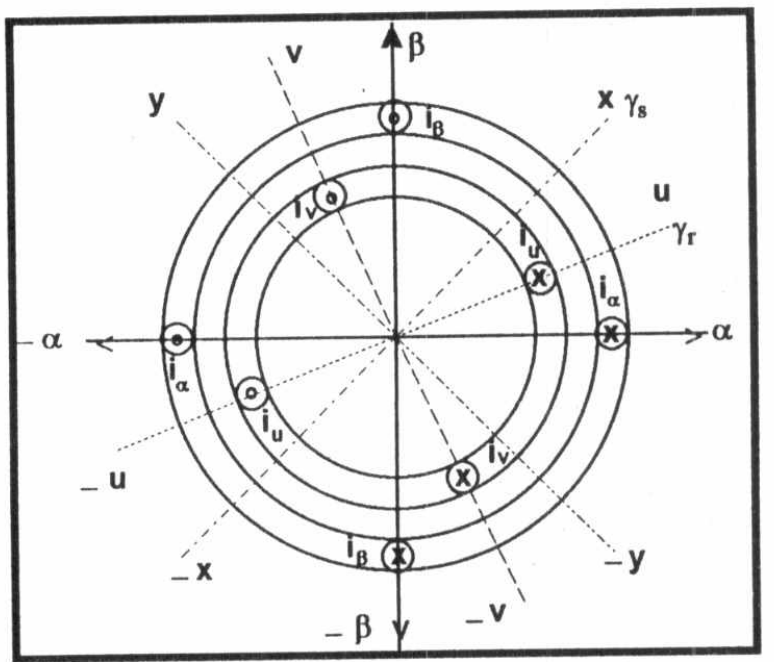

Fig.2 ASM two-poles Model 
In the above equations, all machine parameters and variables can be found by direct measurements. In the following analysis, the reformed variables and parameters are marked by character $(t)$. The values of all resistors and inductors of the mathematical model are smaller by a factor of 1.5 than the corresponding values of the real machine.

If the system of equations given by Eq. 2 is transformed into another frame (x-y) rotating with the stator frequency $\omega_{\mathrm{S}}$, then all variables become constants. The angle between the (xy) rotating coordinates and the $\alpha$-axis of the $(\alpha-\beta)$ stator coordinates is defined as the transformation angle $\gamma_{s}$ and the stator frequency $\omega_{s}$ is the differentiation of that angle.

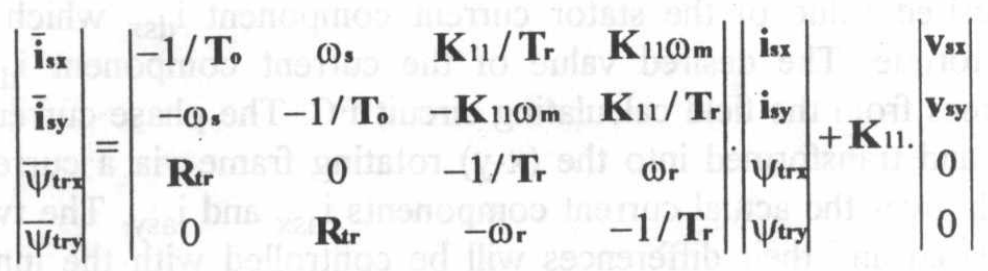

The two-phase $(\alpha-\beta)$ system has been transformed into the rotating system (x-y) by the formula

$\left|\begin{array}{l}\mathrm{G}_{\mathrm{x}} \\ \mathrm{G}_{\mathrm{y}}\end{array}\right|=\left|\begin{array}{cc}\cos \left(\gamma_{\mathrm{s}}\right) & \sin \left(\gamma_{\mathrm{s}}\right) \\ -\sin \left(\gamma_{\mathrm{s}}\right) & \cos \left(\gamma_{\mathrm{s}}\right)\end{array}\right| \cdot\left|\begin{array}{c}\mathrm{G}_{\alpha} \\ \mathrm{G}_{\beta}\end{array}\right|$

If the variables $\mathrm{G}$ represent currents, the square matrix must be multiplied by the factor 1.5.

In order to implement a suitable control scheme, it is preferred to orient the rotating frame so that the $\mathrm{Y}$-axis takes the direction of the rotor field $/ 3 /$. Hence, one obtains the following simplified system of equations.

$\left|\begin{array}{c}\overline{\mathrm{i}}_{\mathrm{sx}} \\ \overline{\mathrm{i}}_{\mathrm{sy}} \\ \bar{\psi}_{\mathrm{try}}\end{array}\right|=\left|\begin{array}{ccc}-1 / \mathrm{T}_{0} & \omega_{\mathrm{s}} & \mathrm{K}_{11} \omega_{\mathrm{m}} \\ -\omega_{\mathrm{s}} & -1 / \mathrm{T}_{\mathrm{o}} & \mathrm{K}_{11} / \mathrm{T}_{\mathrm{r}} \\ 0 & \mathrm{R}_{\mathrm{tr}} & -1 / \mathrm{T}_{\mathrm{r}}\end{array}\right| \cdot\left|\begin{array}{c}\mathrm{i}_{\mathrm{sx}} \\ \mathrm{i}_{\mathrm{sy}} \\ \psi_{\text {try }}\end{array}\right|+\mathrm{K}_{11} \cdot\left|\begin{array}{c}\mathrm{v}_{\mathrm{sx}} \\ \mathrm{V}_{s y} \\ 0\end{array}\right|$

where

$$
\begin{aligned}
& \omega_{r}=-R_{t r} \cdot \frac{i_{s x}}{\psi_{\text {try }}} \\
& T_{e}=-p \cdot\left[\psi_{\text {try }} i_{s x}\right] \\
& J \cdot \bar{\omega}_{\text {mech }}=T_{e}-T_{L}
\end{aligned}
$$




\section{The Control Scheme}

\section{Control Concepts}

The control strategy depends on the change of the two components of the stator current $i_{\text {SX }}$ and $\mathrm{i}_{\text {sy. }}$. As seen from Eq.13 to Eq.15, the stator current component $\mathrm{i}_{\mathrm{sx}}$ is the main factor affecting the induced torque $\mathrm{T}_{\mathrm{e}}$, where the rotor flux is changed by the current component $\mathrm{i}_{\text {sy }}$. For this reason, the former is defined as torque current component and the second flux current component.

Figure 3 shows a compact block diagram for the implemented control strategy. The speed controller WMC gives the desired value of the stator current component $i_{d s x}$ which is proportional to the induced torque. The desired value of the current component $i_{d s y}$, corresponding to the field, comes from the field calculating circuit FC. The phase currents of the machine are measured and transformed into the $(x-y)$ rotating frame via a current vector coordinator $\mathrm{CVC}$ which gives the actual current components $\mathrm{i}_{\text {asx }}$ and $\mathrm{i}_{\text {asy. The two }}$ current components are compared and their differences will be controlled with the inner current control loops IC to give the two components of the desired voltage $v_{d s x}$ and $v_{d s y}$. These dc-voltages are transformed into the rotating three phase system a-b-c using a voltage vector coordinator $\mathrm{VVC}$ to give the desired values of the three phase voltages $\mathrm{v}_{\mathrm{dsa}}$, $\mathrm{v}_{\mathrm{dsb}}$, and $\mathrm{v}_{\mathrm{dsc}}$. According to the PWM principals $/ 5 /$, the firing pulses for the PWI will be generated from these three voltages.

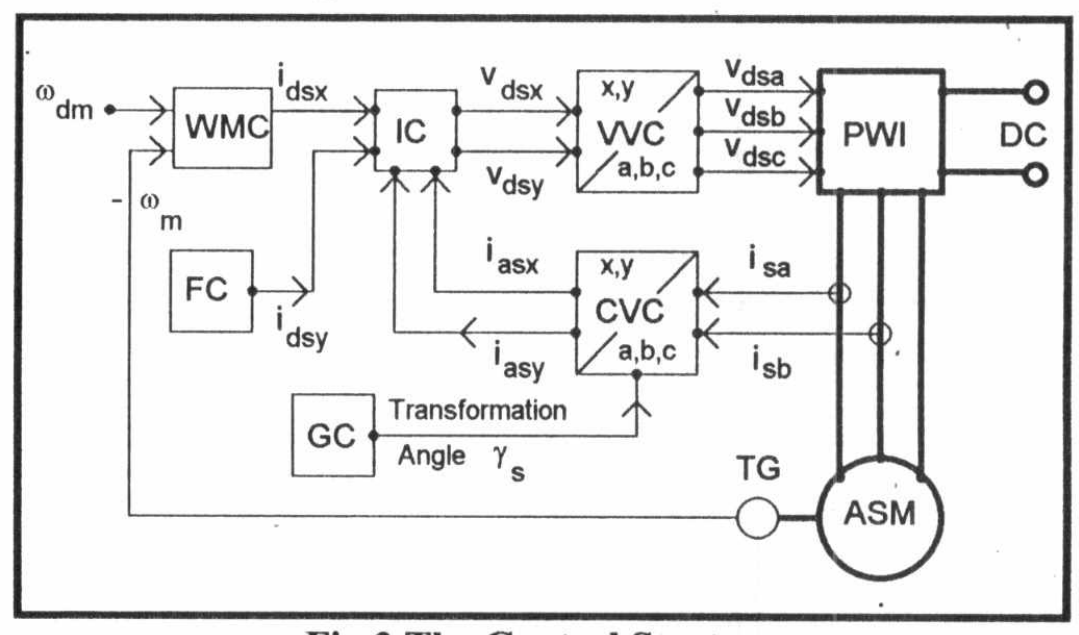

Fig.3 The Control Strategy

There is a second method widely used to control the currents directly for producing the PWM pattern. By this method, the dc-current components $i_{d s x}$ and $i_{d s y}$ are transformed to the three-phase a-b-c coordinating system to obtain the desired values $i_{d s a}, i_{d s b}$, and $i_{d s c}$. The actual three-phase currents $\mathrm{i}_{\text {asa }}, \mathrm{i}_{\text {asb }}$, and $\mathrm{i}_{\text {asc }}$ are measured directly and each of them will be compared with the corresponding desired current. Their differences are individually controlled to obtain the voltage signals from which the firing pattern is produced. Here, one vector coordinator, compared to the first method, is saved. In this method, the steady state currents are sinusoidal waves and by high frequency control errors can be produced. These give wrong values of torque and field which are not proportional to the desired currents $i_{d s x}$ 
$\Gamma$ and $i_{\text {dsy }}$. This occurs especially if there is not enough reserve converter voltage. The implemented method overcomes this disadvantage.

\section{Transformation Angle $\gamma_{s}$}

In order to orient the coordinating system with the field direction, the transformation angle $\gamma_{\mathrm{s}}$ must be kept constant. Its value can be calculated using the relation;

$\gamma_{\mathrm{s}}=\int\left(\omega_{\mathrm{m}}+\omega_{\mathrm{r}}\right) \cdot \mathrm{dt}$

Since there is a high difference between the values of $\omega_{\mathrm{m}}$ and $\omega_{\mathrm{r}}$, a small error in $\omega_{\mathrm{m}}$ gives a considerable error in $\omega_{\mathrm{r}}$ and hence in the field orientation. This disadvantage can be conquered by measuring the rotor angle $\gamma_{\mathrm{m}}$ and using the following relation;

$\gamma_{s}=\gamma_{m}+\int \omega_{r} \cdot d t=\gamma_{m}+\gamma_{r}$

The heat effect on the parameters $/ 4 /$ and the error which may occur due to operation at high frequency $/ 5,6 /$ can be eliminated by calculating the transformation angle $\gamma_{\mathrm{s}}$ through a closed loop. According to the analysis in $/ 2 /$, the rotor emf $e_{t r}$ is given by;

$\mathrm{e}_{\mathrm{tr}}=\bar{\psi}_{\mathrm{tr}}$

This voltage stands approximately perpendicular to the rotor field. Therefore the $y$ component of that voltage equals zero and the $\mathrm{x}$-component is given by;

$e_{\text {trx }}=-\omega_{s} \cdot \psi_{\text {try }}$

The rotor induced voltage of $(\alpha-\beta)$ coordinating system is calculated by relation (21) using the measured variables /7/;

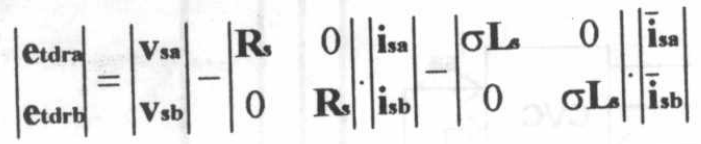

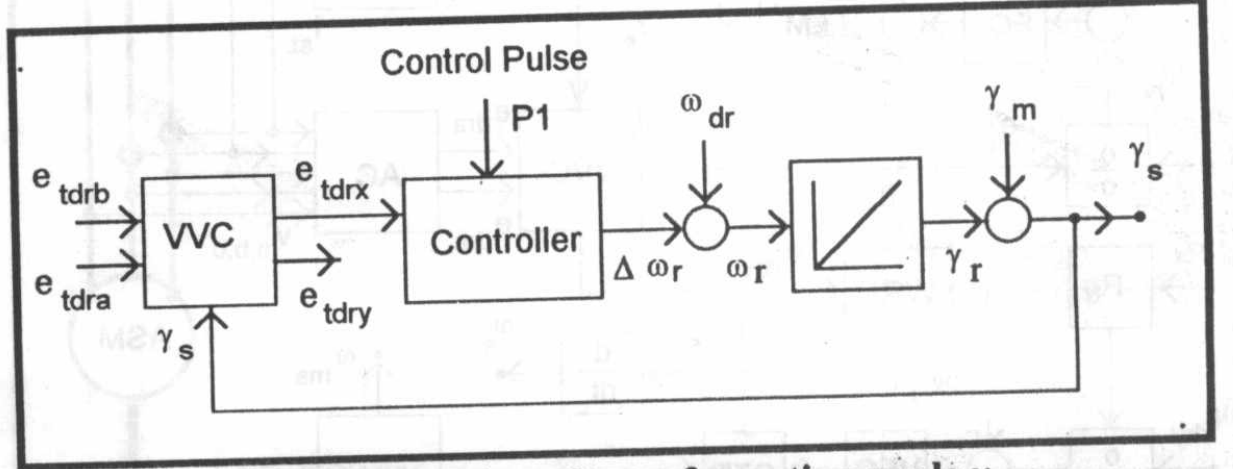

Fig.4 Calculation of transformation angle $\gamma_{\mathrm{s}}$

The block diagram in Fig. 4 shows the calculation of the transformation angle $\gamma_{\mathrm{s}}$. The controller changes the speed $\omega_{\mathrm{r}}$ until the y-component of the induced voltage equals zero. L 
At low stator frequencies, the stator and rotor voltages are also low and the heat effect on the parameters is strong. In this mode of operation, the error of $\gamma_{s}$ is quite high and therefore, the control circuit is opened through a control pulse P1 and a suitable value for the transformation angle $\gamma_{\mathrm{S}}$ is given directly to the control circuit.

\section{Control Of Rotor Flux}

The rotor flux is controlled through a closed loop to obtain the desired stator current field component $i_{d s y}$. The desired value of the rotor flux is given with the flux-speed curve CF covering the field weakening range. The actual rotor flux is calculated using Eq. 20

$\psi_{\text {try }}=-\frac{\mathbf{e}_{\text {trx }}}{\omega_{s}}$

Also at low frequencies, the error ratio by this calculation is quite high because both $\mathrm{e}_{\mathrm{trx}}$ and $\omega_{\mathrm{s}}$ are small values. In this case, the control circuit is opened through a control pulse $\mathrm{P} 1$ and the desired flux value is used directly to calculate the current field component.

\section{Implemented Control Circuit}

The block diagram of the selected control scheme is shown in Fig.5. The control circuits of speed, current components, and field and also the calculation of the transformation angle are implemented according to the analysis discussed before /11/.

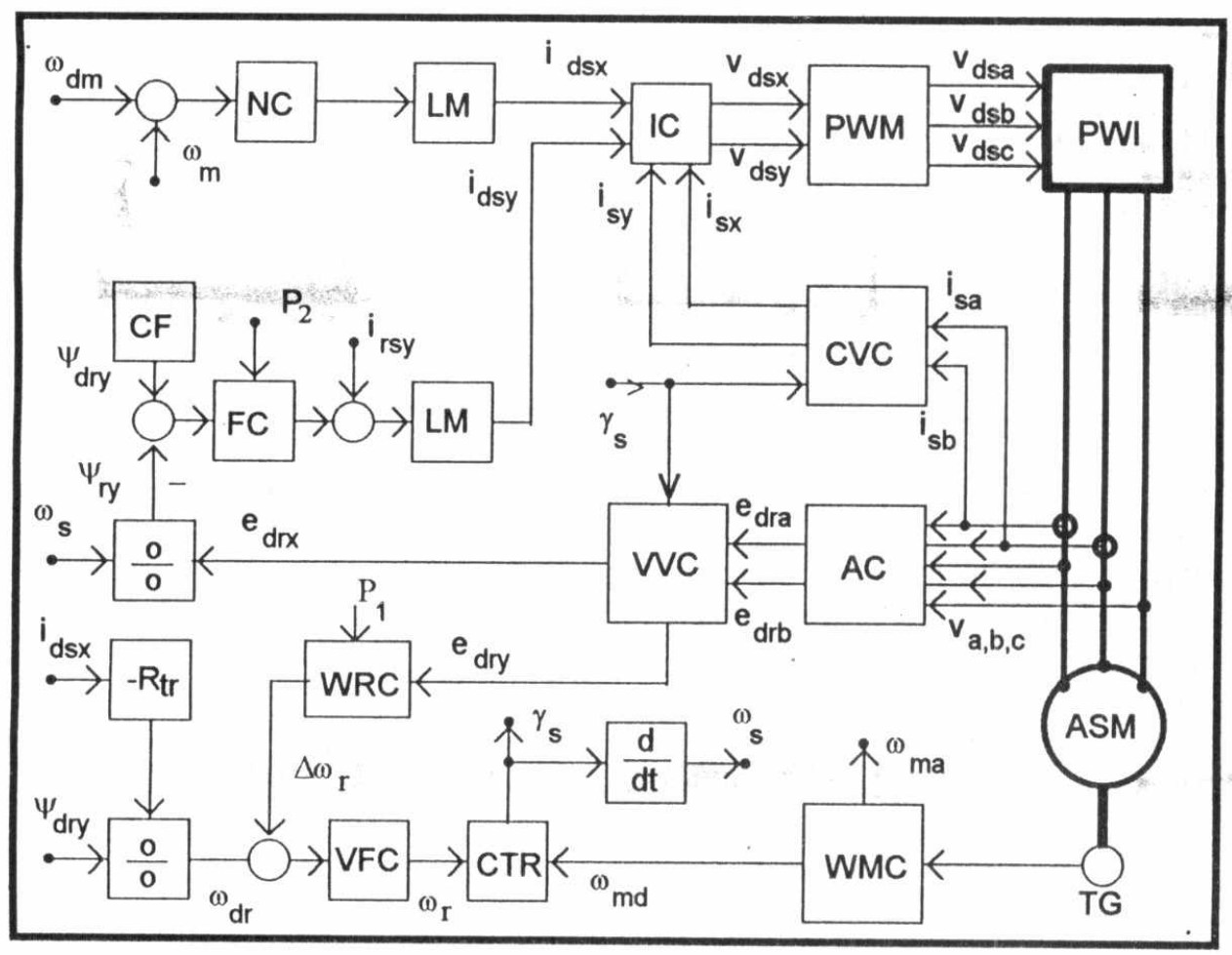


The desired values of the current components are both limited by the LM units. The current vector coordinator CVC supports the pulse width modulation unit PWM with the threephase signals in order to give the wanted pattern signals for the pulse width inverter PWI. The integration of the rotor frequency and also counting the pulses of the incremental speed sensor are performed with one counter only [CRT unit]. Therefore the calculated analog signal corresponding to the rotor frequency must be converted to a digital signal using a voltage to frequency converter VFC. The actual rotor speed is measured by the taco generator TG and manipulating with the unit WMC to obtain the speed into analog and digital forms.

The micro-computing-system performs the control scheme completely and also the generation of the firing signals for the PWI. In order to avoid overloading of the computing system, a part of calculations is implemented with external circuits. These are the circuits which manipulate the measured variables and calculate the transformation angle. Figure 6 shows the overall computing system $/ 10,15 /$.

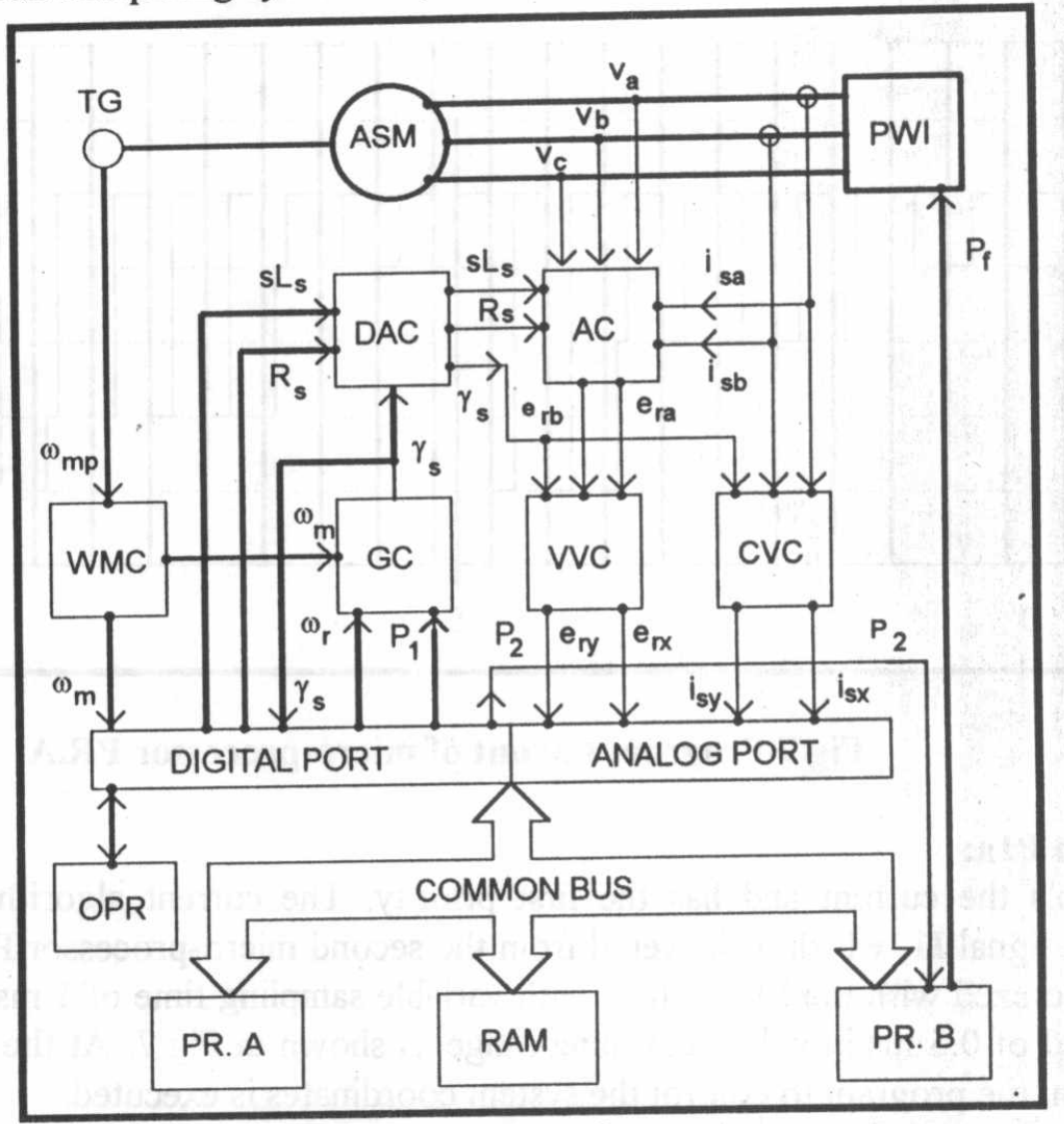

Fig.6 The computing system

The computing system consists mainly of two micro-processors type 8088. Each processor has a local bus-system and EPROM and RAM memories. The first Processor PR.A performs the control scheme, adaptation of parameters and variables, and also communication with the operator OPR. The second Processor PR.B generates the firing pattern for the PWI. The communication between the two processors is fulfilled with a common bus-system. An I/O RAM memory is connected with this bus-system to couple the L two processors and to perform the communication with the analog and digital ports. 
The measured analog variables are transformed into digital words using a 12 bit-ADC. Through samplers, holders, and multiplexer four variables can be synchronously stored and called after another. Also the digital variables needed to the analog calculator AC are converted into analog signals using a 10 bit-DAC. In Fig.6, the digital signals are represented by thick lines where the analog signals by thin lines.

\section{Program Layout}

The micro-Processor PR.A in Fig. 6 performs the control circuits, adaptation of parameters and variables, and also controls the input and output data. Figure 7 shows the time sequence of the different programs executed by micro-processor PR.A in field weakening rang. Each program or interrupt signal is signed with a pulse with a defined level according to its priority. Thus, the program with the highest signal level becomes the first priority to be executed and so on.

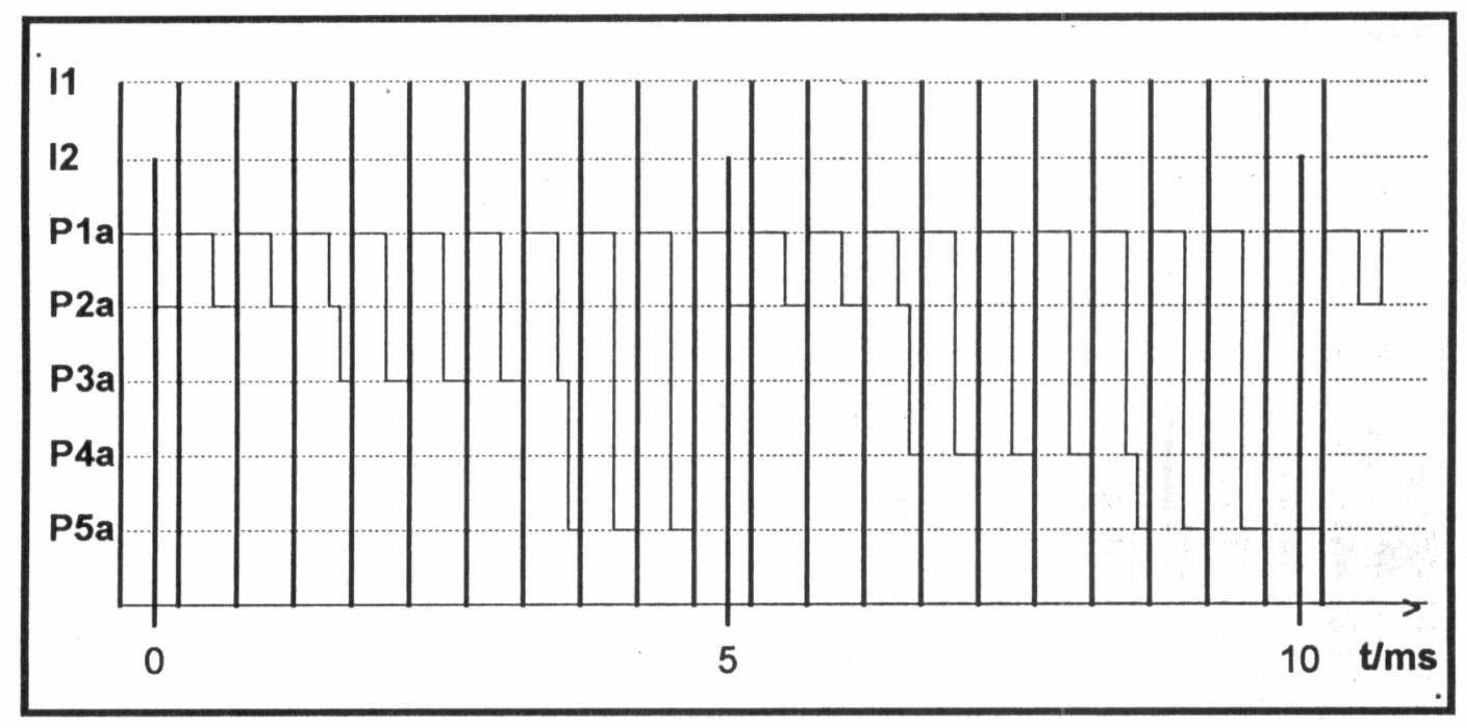

Fig.7 Program Layout of micro-processor PR.A

\section{Program P1a:}

It controls the current and has the first priority. The current algorithm is initialized by interrupt signal I1, which is delivered from the second micro-processor PR.B. The program is synchronized with the PWM, thus with variable sampling time of $1 \mathrm{~ms}$ up to the nominal speed and of $0.5 \mathrm{~ms}$ in field weakening range as shown in Fig.7. At the end of the current algorithm, the program to control the system coordinates is executed.

\section{Program P2a:}

This program performs the speed control and is initialized by the interrupt signal $\mathbf{I} 2$ every $5 \mathrm{~ms}$. The speed measuring unit gives the interrupt signal at the end of any speed measuring period $(5 \mathrm{~ms})$ where a new actual speed value is measured thereafter the speed algorithm is executed. 
Programs P3a and P4a:

After execution of the speed control algorithm, one of these programs will be executed. Program P3a controls the machine field while program P4a calculates the desired value of this field. Any one of these two programs is initialized every 10ms. Program P4a is executed in field weakening range only and in speed normal range another algorithm for adaptation of rotor resistance is performed in this time. Additional programs for parameters measurements can be thereafter performed.

At very low speeds, a short program for field open-loop control is executed after controlling the speed.

\section{Program P5a:}

This is a resident program which communicates some of the measured data to a 7-segment display and also it performs the dialog with the system operator.

\section{Design of controllers}

The design of controller follows the symmetrical optimization rules $/ 8,9 /$. The lag time of the process will be compensated by the controller. Therefore the open-loop control transfer function $\mathrm{F}_{\mathrm{o}}$ consists of an integration time and a non-compensated lag element $\mathrm{F}_{1 \mathrm{~g}}$.

$\mathrm{F}_{\mathrm{o}}=\frac{1}{\mathrm{ST}_{\mathrm{o}}} \cdot \mathrm{F}_{\mathrm{lg}}$

The transfer function $\mathrm{F}_{\mathrm{lg}}$ incorporates the measuring unit and the smoothing element. Generally all the non-compensated time constants are summed to $\mathrm{T}_{\text {sum }}$, and the damping factor of 0.7 is assumed. Therefore, the transfer function of the closed loop becomes a second order element assuming that;

$\mathrm{T}_{\mathrm{o}}=2 . \mathrm{T}_{\text {sum }}$

The used controller is of PI-type and an algorithm is chosen in which the integral part is separately calculated.

$\mathrm{Y}(\mathrm{k})=\mathrm{K}_{\mathrm{P}} \cdot \mathrm{X}(\mathrm{k})+\mathrm{K}_{\mathrm{I}} \cdot \mathrm{X}(\mathrm{k})+\mathrm{Y}_{\mathrm{I}}(\mathrm{k}-1)$

$Y_{I}(k)=Y_{I}(k-1)+K_{I} \cdot X(k)$

Where: $\mathbf{X}(\mathrm{k})$ : the control difference in $\mathrm{k}$-th sampling time.

$\mathrm{Y}:$ Controller output

$\mathrm{Y}_{\mathrm{I}}$ : Integration part.

For a sampling time $\mathrm{T}_{\mathrm{sm}}$, the digital controller becomes a transfer function similar to the analog controller in the form;

$$
F_{\text {controller }}=K_{P}+\frac{K_{1}}{s . T_{s m}}
$$


If the output of the controller exceeds the permissible limits the integration portion is limited to a maximum value. Due to that output limitation, the control loop does not oscillate even when an outer loop is added.

\section{Pulse-Width-Modulation}

The micro-Processor PR.B calculates the wanted conducting states and time-intervals of each transistor in the inverter. It uses the calculated desired values of the amplitude and angle of the stator voltage components in the $\mathrm{x}-\mathrm{y}$ coordinates and also the transformation angle $\gamma_{\mathbf{s}} / 13,14,16 /$

The calculation of the conducting states is according to the principles studied in $/ 5 /$. Any wanted voltage vector V1 as shown in Fig. 8 can be represented in a conducting time $\mathrm{T}$ between the two switching states $\mathrm{S} 1$ and $\mathrm{S} 2$ through three states of the seven states. The calculation gives three conducting times $t_{A}, t_{B}$, and $t_{N}$. In order to have symmetrical PWM by low ratios between conducting time and stator period, the time $t_{N}$ is divided into two times $t_{\mathrm{N} 0}$ and $t_{\mathrm{N} 7}$ corresponding to the zero time vectors $\mathrm{S} 0$ and $\mathrm{S} 7$ respectively. The switching time intervals are given by;

$\mathrm{t}_{\mathrm{A}}=\mathrm{T} \cdot \mathrm{a} / \mathrm{c}$

$t_{B}=T \cdot b / c$

$\mathrm{t}_{\mathrm{N}}=\mathrm{T}-\mathrm{t}_{\mathrm{A}}-\mathrm{t}_{\mathrm{B}}$

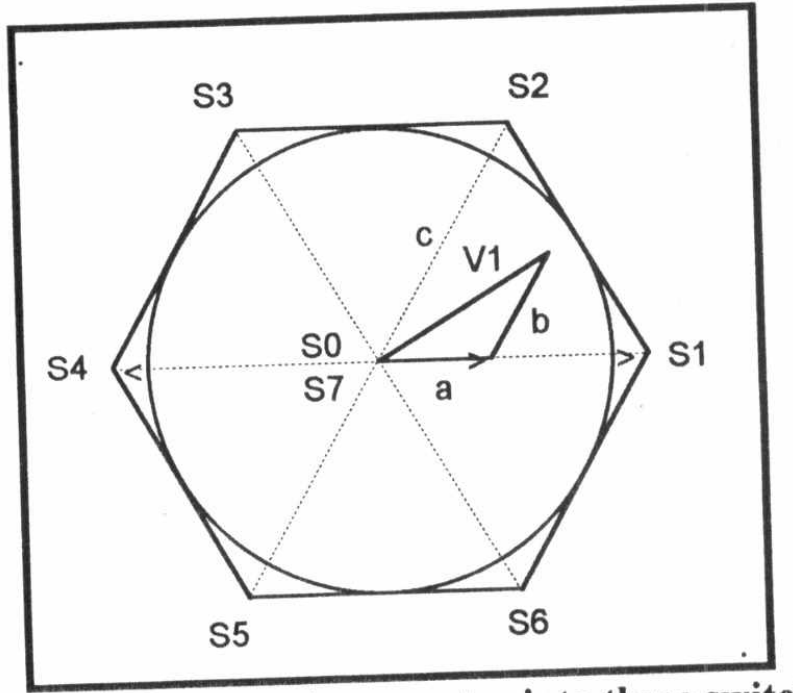

Fig.8 Representation of a voltage vector into three switching states.

According to that analysis, the switching states follow in first in the order $\mathrm{N} 0 \rightarrow \mathrm{A} \rightarrow \mathrm{B} \rightarrow \mathrm{N} 7$, and thereafter in the reversed cycle $\mathrm{N} 7 \rightarrow \mathrm{B} \rightarrow \mathrm{A} \rightarrow \mathrm{N} 0$. The calculated time-intervals will be written in a timer. After expiration of these time-intervals, the processor becomes an interrupt signal to give the next switching states and the corresponding time-intervals. The reaction time of the processor on the interruption limits the minimum conducting interval to $24 \mu \mathrm{s}$ and the shorter time is neglected and added to the next cycle. 
$\Gamma$ Figure 9 shows the time sequence of the different programs executed by the two microprocessors.

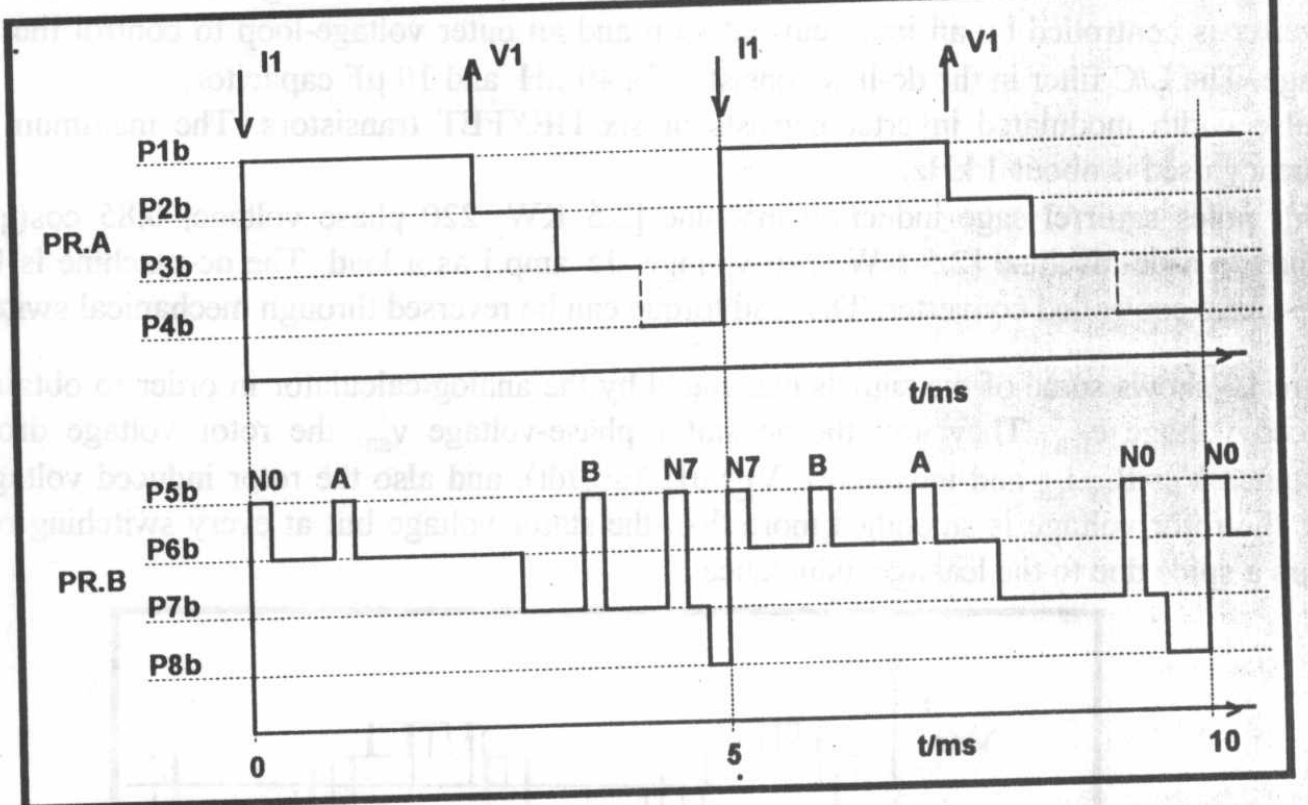

\section{Fig.9 Synchronization of Current control and PWM}

P1b: Current control and transformation of coordinates (Cartesian to Polar).

P2b: Preparation of the next current control algorithm.

P3b: Location of the coordinates.

P4b: Speed control, Field control, and the resident program.

P5b: Output of time intervals and switching states by the interrupt signal from the timer.

P6b: Calculation of stator frequency and cycle period.

P7b: Calculation of time intervals and switching states for the next cycle.

P8b: Resident program.

The output of the first switching state for new cycle (N0 in Fig.9) initializes the calculations of the time intervals of the next cycle and also gives the interrupt signal I1 to the microprocessor PR.A to control the stator current. During calculation of the new desired values by micro-processor PR.A, micro-processor PR.B calculates the stator frequency $\omega_{s}$ by differentiation the transformation angle $\gamma_{\mathbf{s}}$, thereafter it can use the desired values and fixes the time intervals of the new cycle and prepare the next algorithms for execution.

There is a dead time between the calculation of the transformation angle $\gamma_{\mathbf{s}}$ and the calculation of switching states. The mean value of this time is about 1.5 of the sampling time $\mathrm{T}_{\mathrm{sm}}$. Therefore, the transformation angle $\gamma_{\mathrm{s}}$ is corrected by;

$\Delta \gamma_{\mathrm{s}}=1.5 . \omega_{\mathrm{s} .} \mathrm{T}_{\mathrm{sm}}$ 


\section{Results}

The implemented system consists of::

1. A three-phase converter used as a dc-source connected to the net through an auto-transformer. The converter is controlled by an inner current-loop and an outer voltage-loop to control the output dcvoltage. The $\mathrm{L} / \mathrm{C}$ filter in the dc-link consists of a $40 \mu \mathrm{H}$ and $10 \mu \mathrm{F}$ capacitor.

2. A pulse width modulated inverter consists of six HEXFET transistors. The maximum switching frequency used is about $1 \mathrm{kHz}$.

3. A four poles squirrel cage induction machine [ $2.5 \mathrm{KW}, 220$ phase voltage, $0.85 \cos (\varphi), 50 \mathrm{~Hz}]$ coupled to a dc-machine [2.5 KW, 220 voltage, $15 \mathrm{amp}$.] as a load. The dc-machine is fed from a three-phase controlled converter. The load torque can be reversed through mechanical switches.

Figure 10 shows some of the signals calculated by the analog calculator in order to obtain the rotor induced voltage $\mathrm{e}_{\mathrm{tsa}}$. They are; the ac stator phase-voltage $\mathrm{v}_{\mathrm{sa}}$, the rotor voltage drops on the resistance $\mathrm{V}_{\mathrm{R}}=\mathrm{R}_{\mathrm{sa}} \cdot \mathrm{i}_{\mathrm{sa}}$ and inductance $\mathrm{V}_{\mathrm{L}}=\sigma \mathrm{L}_{\mathrm{s}} \cdot\left(\mathrm{di}_{\mathrm{sa}} / \mathrm{dt}\right)$, and also the rotor induced voltage $\mathrm{e}_{\text {tra. }}$. As seen, the rotor voltage is smoothed more than the stator voltage but at every switching of the PWI occurs a spice due to the leakage inductance.

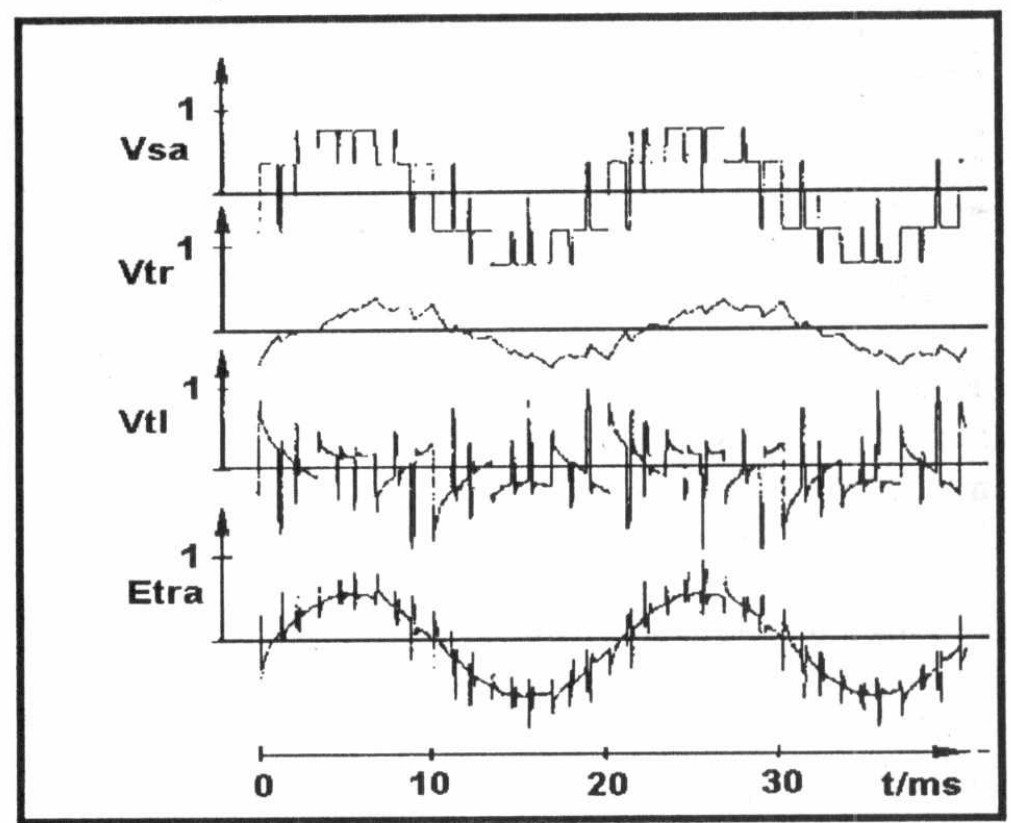

Fig.10 Calculation of rotor induced voltage $e_{\text {tsa }}$

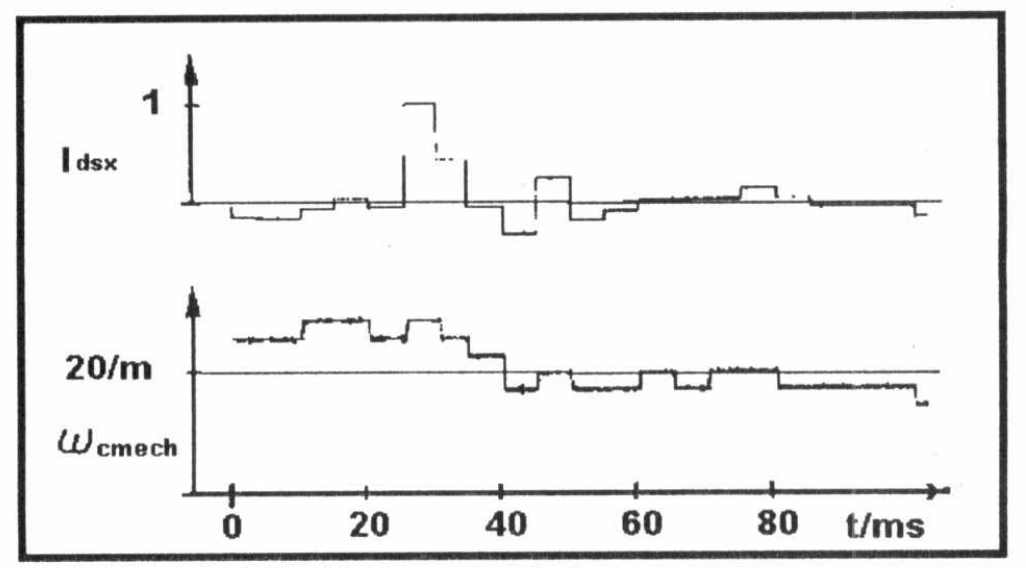

Fig.11 the no-load characteristics 


\section{Conclusion}

In this paper, a control scheme for a pulse width modulated drive system comprising a squirrel cage induction machine is analyzed and then implemented. All algorithms to verify the control scheme and to produce the firing pattern for the PWI are performed using a computing micro-processor-system. The rest of the system is implemented either by digital or analog circuits. The firing pattern for the PWI depends on voltage signals corresponding to the phase voltage instead of phase currents in order to eliminate the torque and field errors. As seen from the measured curves, the speed can be dynamically changed for a wide range in the field weakening range and the maximum source voltages and currents are fully used. This proves, that the system is stable and suitable to be applied in industrial applications.

\section{References}

1. Jotten R. : " Stand der Technik bei geregelten Drehstromantrieben"; VDE-Fachberichte 30, VDE-Verlag Berlin, 1978.

2. Salah Gh. Ramadan: "Speed Control of an Induction Machine Drive System"; 14Th. INT. CONF. for STAT. , Comp., \& DEMO. RES., CAIRO 25-30 MARCH 1989., 2ND. Vol. 39-53.

3. F. Blaschke " The principle of Field orientation As Applied to the new Transvector Closed-loop Control System For Rotating field Machines" Siemens Review, Vol. 34, pp. 217-220, May 1972.

4. Garces, J. L. : "Ein Verfahren zur Parameteranpassung bei der Drehzahlregelung der umrichtergespeisten Kaefiglaeufermaschine", Diss. Darmstadt, 1979.

5. Eibel, J. : " Ein Verfahren zur Parameteranpassung bei der Drehzahlregelung der umrichtergespeisten Kaefiglaeufermachine", Diss. Darmstadt, 1979.

6. Seifert D. : "Stromregelung der Asynchronmaschine etz-Archiv Band 8, Heft 5, 1986.

7. J. Holtz, E. Bube : "Field-Oriented asynchronous PWM for high-performance ac machine drive operating at low switching frequency" IEEE Industry Applications, vol. 27, No.3, May/June 1991 messbarer Groessen", Diss. Darmstadt, 1981.

8. R. Gabriel W. Leonarhrad and C. Nordby : " Field Oriented control of A standard Ac Imotor Using Microprocessors" IEEE Industry Applications, Vol. . IA-16, pp. 186-192 Mars/April 1980.

9. Schierling H. : "Selbsteinstellendes und selbstanpassendes Antriebsregelsysteme mit Pulswichselrichter" Dissertation Darmstadt, 1987.

10. R. Gabriel W. Leonarhrd : " Microprocessor control of Induction Motor" IEEE Industry Applications, Society Annual Meeting pp. 385-395, 1982.

11. R. W. Doncker and D. W. Novotny : " The Universal field oriented controller" IEEE Industry Applications Society Annual Meeting., pp. 450-456, 1988.

12. Y. Murai, T. Watanabe and H. Iwaski : "Wave form Distortion and Correction Circuit for PWM Inverters with Switching Lag-Times, "IEEE Industry Applications, Vol. IA-23, No. 5 September/October 1987.

13. J. Holtz and B. Beyer : "Off-line optimized synchronous PWM with on-line control during transients, "European Power Electronics and Drives Journal, December 1991.

14. A. Busse and J. Holtz : "A digital space vector modulator for the control of a three-phase power converter, " VDE-Konference Mikroelektronik in der Stromrichtertechnik und bei elektrischen Antrieben, Darmstadt, November 1982, pp. 189-195.

15. Y. Mauri, T. Watanabe and H.Iwasaki : "Wave form distortion and correction circuit for PWM inverter with switching lag-Times" IEEE Industry Applications, Vol. IA-23, No.5, pp. 881885, Sep/Oct.1987.

16. T. Sukegawa, K. Kamiyama, K. Mizuno, T. Matsui and T. Okuyama : "Fully Digital, Vector-Controlled PWM VSI-Fed ac Drives with an Inverter Dead Time Compensation Strategy" L IEEE Industry Applications, Vol. 27, No. 3, May/June 1991. 
$\Gamma$ Figure 11 illustrates the no-load characteristics of the speed controller where a unit step change of the desired speed is applied from $30 \mathrm{rpm}$ to $20 \mathrm{rpm}$. The calculated actual speed ${ }^{\omega_{\mathrm{Cmech}}}$ and the corresponding stator current component $i_{\mathrm{dsx}}$ responsible for the induced torque are shown.

In Fig. 12 the dc machine is suddenly loaded by a step change of load current of $i_{d l}$. The registered curves are; the actual load current $i_{1}\left(\approx i_{d c}\right)$, the calculated desired stator current components $i_{\mathrm{dsx}}$, the actual calculated speed $\omega_{\mathrm{Cmech}}$, and the corresponding real motor speed $\omega_{\text {mech }}$. The calculated speed $\omega_{\text {Cmech }}$ swings by an increment and this produces current and torque ripples. Therefore this speed signal is smoothed before feeding the speed controller in order to reduce the ripples of its output current $i_{d s x}$.

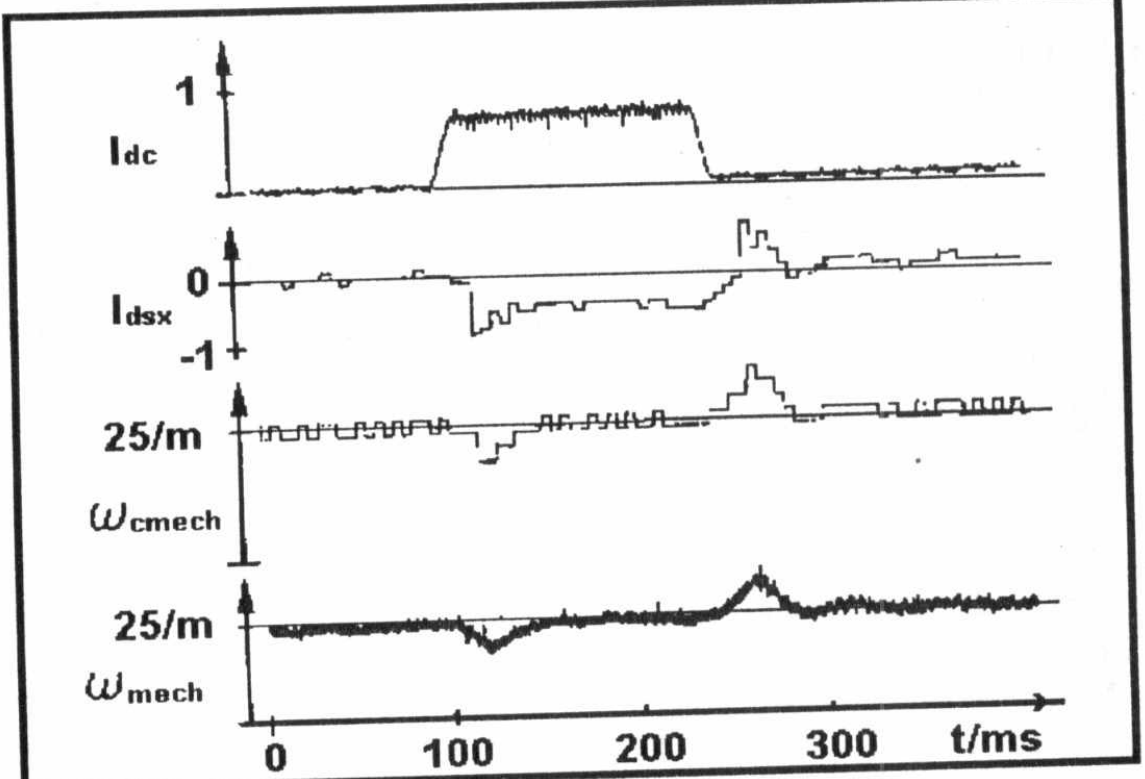

Fig.12 Step change of load current

Figure 13 shows a speed reversing procedure at no-load from $+3000 \mathrm{rpm}$ to $-3000 \mathrm{rpm}$. It is clear, that during acceleration control of the voltage source reached its maximum limits. The actual stator current component (output of speed controller) $i_{\text {sx }}$ deviates from the corresponding desired value with a negligible value. The operation in field weakening range is clear.

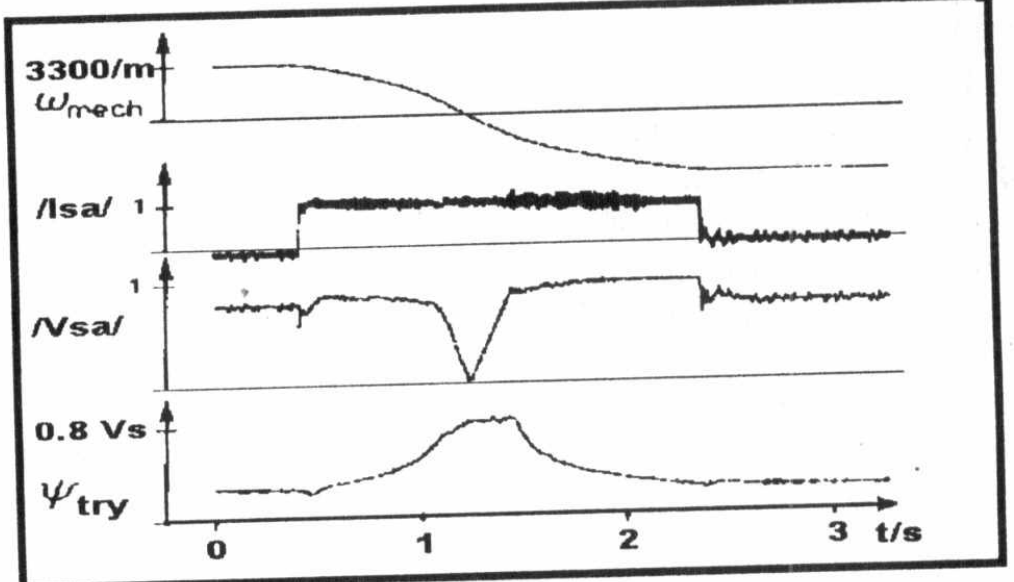

Fig.13 Speed reversing mode 